\title{
Asymptomatic Colonic Anisakiasis
}

\author{
Yasuyuki Tamai and Kazuhiko Kobayashi
}

Key words: anisakiasis, colon

(Intern Med 54: 675, 2015)

(DOI: 10.2169/internalmedicine.54.3649)

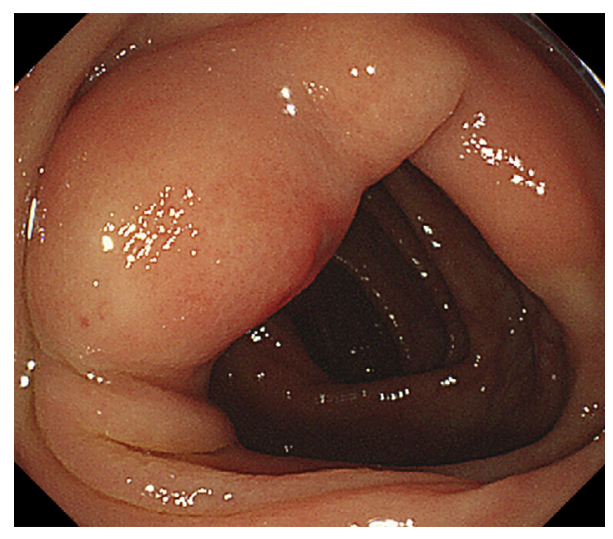

Picture A.

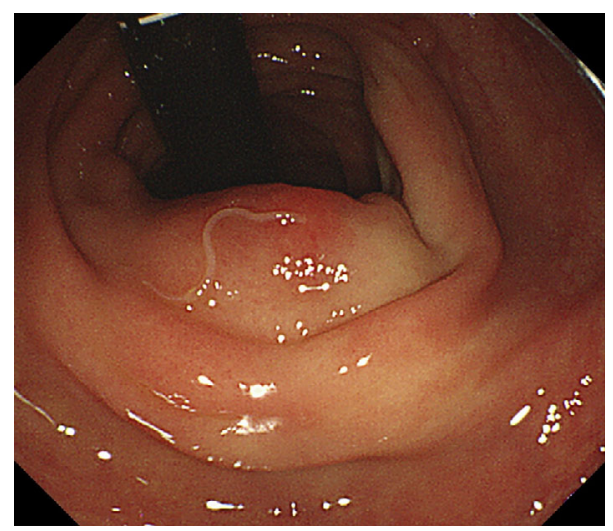

Picture C.

A 41-year-old woman was admitted to our hospital with a diagnosis of colon adenoma in an asymptomatic condition. Endoscopic mucosal resection incidentally revealed a submucosal tumor (SMT) in the ascending colon. The diameter of the tumor was approximately $3 \mathrm{~cm}$, and the lesion was accompanied by surface erosion (Picture A, B). Colonoscopy performed at the previous hospital did not disclose

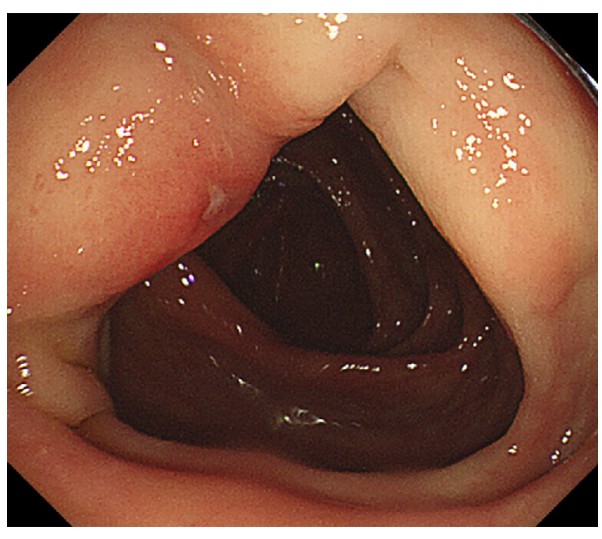

Picture B.

the tumor. When the colonoscopy image was inverted, an Anisakis larva was found behind the tumor (Picture C): the Anisakis larva was therefore removed using forceps. We subsequently discovered that the patient had eaten raw squid two days before admission. Anisakiasis is a human parasitic infection of the gastrointestinal tract, particularly the stomach. It is reported in geographic areas where fish is consumed raw, including Japan; however, anisakiasis of the colon is rare and often manifests as SMT (1). Therefore, some cases may be rediagnosed as colonic anisakiasis following surgery for SMT (2).

The authors state that they have no Conflict of Interest (COI).

\section{References}

1. Herranz-Bachiller MT, Atienza-Sánchez R, Barrio-Andrés J, et al. Colonic polyp secondary to Anisakis simplex. Rev Esp Enferm Dig 104: 554-555, 2012.

2. Yorimitsu N, Hiraoka A, Utsunomiya $\mathrm{H}$, et al. Colonic intussusception caused by anisakiasis: a case report and review of the literature. Intern Med 52: 223-226, 2013.

Department of Gastroenterology, Matsusaka Chuo General Hospital, Japan

Received for publication July 9, 2014; Accepted for publication August 3, 2014

Correspondence to Dr. Yasuyuki Tamai, yasuyuki.tamai@miekosei.or.jp

(C) 2015 The Japanese Society of Internal Medicine Journal Website: http://www.naika.or.jp/imonline/index.html 